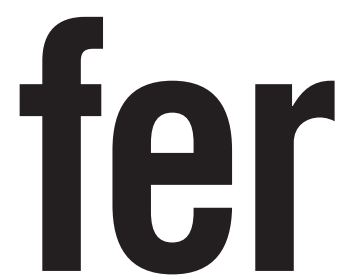

Family and

\section{Environment}

\section{Research}

\title{
Body Image Dissatisfaction and Self-esteem among Korean Pre- and Early Adolescent Girls and Boys: A Five-year Longitudinal Panel Study \\ Woochul Park' \\ ${ }^{1}$ Department of Human Development and Family Studies, Duksung Women's University, Professor
}

후기 아동기 및 초기 청소년의 신체상불만족과 자존감: 종단적 패널 연구

박우철 ${ }^{1}$

${ }^{1}$ 덕성여자대학교 아동가족학과 교수

\section{Abstract}

Longitudinal studies have shown mixed findings on the association between body image dissatisfaction and selfesteem among adolescents. This study examined the longitudinal, reciprocal influences between body image dissatisfaction and self-esteem among Korean pre- and early adolescents by using nationally representative longitudinal panel data from the Korean Youth Panel Study (KYPS). Analyses based on 2,230 participants indicated that girls' body image dissatisfaction was significantly higher than boys.' The trajectory of body image dissatisfaction increased sharply during pre- and early adolescence, but stabilized afterwards for both boys and girls. Self-esteem deteriorated rapidly initially, but began to recover as adolescent girls and boys matured. Structural equation modeling showed that reciprocal influences between body image dissatisfaction and self-esteem were detected for boys. Body image dissatisfaction among girls predicted self-esteem during the entire period, while the opposite direction from self-esteem to body image dissatisfaction emerged two years later. The present study found that, during pre- and early adolescence, body image dissatisfaction and self-esteem develop in a circular fashion by forming a vicious cycle. Implications for the development of intervention and prevention programs are discussed in consideration of age and gender.

Keywords

body image dissatisfaction, self-esteem, pre- and early adolescence, gender

\section{Body image dissatisfaction and self-esteem in adolescence}

Body image is commonly conceptualized as an "internal representation of one's own outer appearance- one's own unique perception of one's body." (Thompson et al., 1999, p.

Received: December 14, 2019 Revised: January 28, 2020 Accepted: February 17, 2020

\section{Corresponding Author:} Woochul Park

Department of Human Development and Family Studies, Duksung Women's University/(01369) 33, Samyang-ro 144gil, Dobong-gu, Seoul, Republic of Korea. Tel: +82-2-901-8369 E-mail: sentip1979@duksung.ac.kr
4). Body image is a multidimensional construct involving diverse cognitive, emotional, and behavioral responses; therefore, body image has been defined depending on what body image dimension is focused on. Among the definitions, body image dissatisfaction focusing on one's negative perception of and emotional responses to one's body is the most widely used term in the field (Thompson et al., 1999).

Adolescents' body image dissatisfaction has been of interest among scholars due to the importance of body image as distinct developmental features during adolescence. In a physical aspect, adolescence is a period of rapid bodily changes due to secondary sex characteristics (Coleman \& Coleman, 2002). The drastic bodily changes that adolescents 
go through amplify interests in and concerns about their body (Gatti et al., 2014). Compared to other stages of development, adolescence is also the stage when one becomes conscious of other people (Somerville et al., 2013). It is important for adolescents to understand how they are viewed by others. Adolescents create an imaginary audience that evaluates their outward self represented by their appearance (Elkind, 1967).

Body image dissatisfaction has been investigated in its relation to adolescents' self-esteem, since self-esteem is a an important component in adolescent life. Selfesteem becomes important during adolescence due to cognitive developmental changes. Cognitive abilities such as integration emerging since middle childhood allow adolescents to construct a global self-concept (Harter, 1999). For instance, based on the ability of integration, adolescents combine separated specific behavior or events in their lives, such as, 'getting high scores in math' and 'being popular among peers', into a higher-order and abstract concept about self, such as 'I am a very good person.'

Numerous studies have investigated the nature of the relationship between body image dissatisfaction and selfesteem due to their important features in adolescents' lives. From a theoretical perspective, both causal pathways from body image dissatisfaction to self-esteem and from self-esteem to body image dissatisfaction are theoretically meaningful. First, the direction from body image dissatisfaction to self-esteem inquires whether the perceived appearance determines global self-worth. The direction is based on empirically-supported William James' (1890) self-discrepancy model (Harter, 1999) that argues an individual's success in specific domains where he or she has aspirations to succeed produces high self-esteem because it facilitates congruence between an ideal and real self in such domains. Conversely, lack of success in domains of desire lowers self-esteem because it generates discrepancy between the ideal and real self. It becomes possible after middle childhood to differentially value certain areas more highly than others and compare two representations of real and ideal self. They also begin to place greater importance on their body as they move into adolescence (Harter, 1999). Consequently, it can be hypothesized that the effect of body image dissatisfaction on self-esteem would be robust in adolescence. Furthermore, the perception of body would be more influential than other domains in the construction of self-esteem in adolescence because, unlike other domains of self which are bound to specific contexts (academic achievement and athletic competence), body is omnipresent by nature wherever the self is present.

Conversely, the opposite direction from self-esteem and body image dissatisfaction examines if someone holds negative attitudes and feelings toward themselves, then they also will be dissatisfied with their body. From a clinical perspective, this path derives from the etiology of eating disorders (an indicator of a severe body image disturbance) where low self-esteem is a necessary condition for the development of eating disorders (Polivy \& Herman, 2002; Silverstone, 1992). For developmental psychologists focusing on self-processes, this pathway relates to if an individual' s global evaluation of the self influences their evaluation of domain-specific attributes. Global feelings towards the self may easily permeate how one views their looks since the body is ubiquitous wherever the self is. Harter (1999) argued the direction from global self-worth to body image dissatisfaction is plausible and reported approximately $40 \%$ of adolescents believed that this direction describes the nature of the relationship between the two variables better than the opposite path, while 60\% supported the opposite one. Interestingly, girls who supported the direction from self-esteem to body image showed higher self-esteem and lower body image dissatisfaction than their counterparts (Harter, 1999).

Whether the causality of the relationship is unidirectional or bidirectional has an important implication in understanding developmental trajectories of body image dissatisfaction and self-esteem in pre- and early adolescence. If the causality is reciprocal and circular rather than linear in the long term, it means that the relationship of body image dissatisfaction and low self-esteem gradually develops via a vicious cycle. Individuals who experience 
increased body image dissatisfaction will suffer deteriorated self-esteem, which will again intensify their body image dissatisfaction that forms an escalated vicious cycle between them. This might accelerate outbreaks of severe clinical problems such as eating disorders and depression that are indicators of excessive body image dissatisfaction and worsened self-esteem.

\section{Body image dissatisfaction and self-esteem: Empirical} studies and limitations

A robust relationship between self-esteem and body image dissatisfaction among adolescents is welldocumented in the literature of cross-sectional studies. Studies reporting bivariate correlations between body image and self-esteem in the U.S. have shown moderate to high associations ( $r=.38$ to .80) (Harter, 1999; Shaw et al., 2004; Shroff \& Thompson, 2006). Similar correlations have been found in samples from other countries (Dorak, 2011; Harter, 1999), in various ethnic groups (e.g., Latino youth; Mirza et al., 2011), and in diverse age groups ranging from young children to adults (Harter, 1999). The correlations between body image dissatisfaction and self-esteem are also significantly higher than those found between other characteristics and self-esteem such as scholastic competence, social acceptance, behavioral conduct, and athletic competence (Harter, 1999).

Cross-sectional studies conducted in many countries (including Korea) that used regression analyses and theoretically based directional hypotheses (with body image dissatisfaction considered an independent variable that is hypothesized to influence self-esteem) also have indicated an association between body image dissatisfaction and selfesteem (Delfabbro et al., 2011; Frost \& McKelvie, 2004; Han \& Kim, 2006; Mendelson et al., 1996; Park \& Choi, 2008; Polce-Lynch et al., 2001). The opposite causal pathway, from self-esteem toward body image dissatisfaction, has also been supported in cross-sectional studies (Ata et al., 2007; Brunet et al., 2010; Kostanski \& Gullone, 1998; Makinen et al., 2012; Mendelson et al., 1996).

Cross-sectional studies offer information on the association between variables at a certain point in time; however, cross-sectional studies cannot provide information on the temporal order required to identify the direction of causality between variables. Therefore, several prospective studies have been conducted in order to clarify the temporal pathway between body image dissatisfaction and selfesteem. However, findings have been mixed in the literature unlike the consistent findings in cross-sectional studies.

Studies conducted in Australia and Europe on the path from body image dissatisfaction to self-esteem have supported such a direction (Birkeland et al., 2012; Johnson \& Wardle, 2005; Tiggemann, 2005). However, a study performed in Canada (Mendelson et al., 1996) indicated that the level of esteem regarding one's body predicted selfesteem two years later among adolescents aged 11 to 13, but not among younger ones (aged 8 to 10). A study conducted in Korea (Park \& Epstein, 2013) also reported that body image predicted the self-esteem of the subsequent year only for adolescent girls, but not for boys.

For the opposite direction from self-esteem to body image dissatisfaction, Paxton et al. (2006) reported that self-esteem predicted body dissatisfaction five years later for girls, but not for boys. Park \& Epstein (2013) found that self-esteem for 14-year old Korean adolescents predicted body image dissatisfaction one year later for both genders. However, studies by Mendelson et al. (1996) in Canada and Tiggemann (2005) in Australia found that the self-esteem of adolescents failed to predict subsequent body image dissatisfaction. Thus, further longitudinal investigations are warranted because it is premature to assume bidirectional and reciprocal influences between body image dissatisfaction and self-esteem among adolescents due to the existence of contradictory findings (Mendelson et al., 1996; Tiggemann, 2005).

Prior research has also had other limitations that need to be addressed with additional studies. Adolescence usually denotes "the period of human development that starts with puberty (10-12 years of age) and ends with physiological maturity (approximately 19 years of age)" (American Psychological Association (APA), 2007, p. 21); 
however, most cross-sectional and prospective studies on adolescent body image dissatisfaction and self-esteem have focused on mid- or late-adolescence (approximately ages 14 to 18). Consequently, there is a lack of knowledge on the relationship between body image dissatisfaction and self-esteem during the transition period from preto early adolescence. The present study utilizes panel data encompassing preadolescence ( $4^{\text {th }}$ grade of elementary school) and early adolescence ( $5^{\text {th }}$ grade of elementary school to $2^{\text {nd }}$ grade of middle school) to address this issue.

A second limitation of prior longitudinal studies is their use of only two time points for assessment. Thus, they have not addressed how the temporal association between body image dissatisfaction and self-esteem may change over time. Some cross-sectional analyses that included subsamples of different age groups found that the degree of association between body image dissatisfaction and selfesteem differed by age group (Mendelson et al., 1996; Polce-Lynch et al., 2001). For example, in Mendelson et al.'s study, the variance in self-esteem that body-esteem accounted for was larger for mid-adolescents ( $M=14.2$ years) than for early-adolescents ( $M=10.4$ years), which suggests that the importance of body-esteem in relation to self-esteem may be greater in middle adolescence than early adolescence. However, such comparisons by age have never been conducted in longitudinal panel studies with multiple waves with a single cohort. Also, in order to investigate the long term reciprocal, circular relationship between body image dissatisfaction and self-esteem, longitudinal panel studies with a series of waves are called for.

Furthermore, except for one study (Park \& Epstein, 2013) that used a nationally representative sample, all previous studies have used convenience samples (Mendelson et al., 1996; Tiggemann, 2005) or locally representative samples collected in western Norway and in the North West of England (Birkeland et al., 2012; Johnson \& Wardle, 2005). Therefore, there is a limited degree to which findings from the previous studies may be generalized. Nationally representative data are needed to strengthen the external validity of research findings on this topic.
Lastly, most longitudinal studies did not separate gender in analysis (e.g., Birkeland et al., 2012) or sampled only female adolescents (Johnson \& Wardle, 2005; Tiggemann, 2005). This is problematic, given the gender differences a previous study detected (Park \& Epstein, 2013). Specifically, the causal direction from body image to self-esteem was significant only for girls, not for boys, which may be due to the sociocultural influence of peers, media, and family members that distribute the message that body/appearance is more important for women than for men (HaworthHoeppner, 2000; Heinberg \& Thompson, 1995). Such gender differences are also found with regard to the opposite direction from self-esteem and body image dissatisfaction. A five-year longitudinal study (Paxton et al., 2006) detected a unique set of predictors of body image dissatisfaction by gender, where self-esteem predicted body image dissatisfaction only for girls and not for boys. Therefore, studies stratifying gender in analysis are needed in order to clearly understand the relationship between body image dissatisfaction and self-esteem.

\section{Korean adolescents' body image from a cultural perspective}

The high level of focus by adolescents on their body image and self-concept are observed universally (Harter, 1999). However, the link between body image and general self-concept is assumed to be particularly strong in Asian cultures. The collectivist quality of Asian cultures leads individuals to place a high priority on interpersonal relationships and be sensitive to the cues of external evaluations (Cohen \& Hoshino-Browne, 2005; Nisbett, 2003). In this cultural context, body image, as a core aspect of the socially constructed self, may have a significant influence on general self-esteem. However, few studies have been conducted in Asian countries regarding the association between adolescents' body image and psychological functioning (Jackson \& Chen, 2010; Mellor et al., 2009; Park \& Epstein, 2013; Xu et al., 2010). 
South Korea may deserve special attention in research on body image dissatisfaction and self-esteem due to the distinctive centrality of body/appearance in Korean society. Koreans are the thinnest among peoples of the Organization for Economic Co-operation and Development (OECD) countries (OECD, 2011); however, the desire to lose weight by Korean young women was the highest among 22 countries (Wardle et al., 2006). Per capita, plastic surgery procedures in Korea were also the highest in the world (International Society of Aesthetic Plastic Surgeons, 2010). Body/appearance-related stress was reported as the second most serious stress among Korean male and female adolescents, following academic-related pressures (Statistics Korea, 2011). Furthermore, Korean adolescents experience body/appearance-related discrimination more often than adolescents in China, the United States, and Sweden (National Youth Policy Institute, 2008), while a recent study reported no association between obesity and bullying victimization from peers among Korean middle school students (Kim et al., 2016).

The preoccupation with body appearance in Korea is notable, even when compared with other East Asian countries. Korean college students of both genders are more likely than counterparts in China and Japan to believe that it is fine to change one's body artificially. They also tend to place higher priority on body appearance than on health and evaluate their bodies from the viewpoints of others compared to Chinese and Japanese students (Gim \& Ryu, 2012). Koreans tend to associate physical attractiveness with intellectual capabilities, success in one's career, and family harmony (Sung et al., 2009). In such a body/ appearance-centered society, adolescents seem likely to suffer from dissatisfaction related to body image, and body image dissatisfaction may have a negative effect on their global self-concept as soon as early adolescence. Therefore, there is a clear need for research on the association between body image dissatisfaction and self-esteem among early adolescents in Korea.

The purpose of this study is to investigate the longitudinal relationship between Korean pre- and early adolescents' body image dissatisfaction and self-esteem over time using nationally representative panel data. The study also provides information about the development of body image dissatisfaction and self-esteem in pre- to early adolescence.

The study suggests the following research questions.

1. Are there age and gender differences in body image dissatisfaction and self-esteem over time?

2. Do body image dissatisfaction and self-esteem predict each other over time for both genders?

\section{Methods}

\section{Data and sample}

This study used the Korean Youth Panel Study (KYPS; National Youth Policy Institute, 2010) that followed a cohort of over 2,500 adolescents born between March, 1994 and February, 1995. The study was conducted for five years, from 2004 to 2008, from the time when the sample began the fourth year of elementary school through the second year of middle school. KYPS items cover a broad range of topics in order to grasp the general development trend of adolescents such as deviant behavior, everyday activities, self-identity, and life stresses. The survey utilized a stratified multi-stage cluster sampling in the Seoul metropolitan area as well as 14 other metropolitan cities and provinces. Participants were surveyed at school for the first year, whereas in subsequent years, they were tracked with individual interviews conducted at pre-arranged times and places. Participants who failed to complete the survey or missed their appointment were scheduled for an additional interview to minimize attrition. Major reasons for attrition included strong refusal, loss of contact, students' overseas study and emigration.

This study operationally defined adolescence as between the ages of 10 to 19 based on guidelines of the World Health Organization (WHO) and American Psychological Association (APA). WHO defined adolescents "as those people between 10 and 19 years of age" (WHO, 2020). APA 
Family and Environment Research

Table 1. Mean Scores for Body Image Dissatisfaction and Self-esteem over Time

\section{Boys $(n=1,170)$}

\begin{tabular}{|c|c|c|c|c|c|}
\hline Measure & Time $1(M=9.9)$ & Time $2(M=10.9)$ & Time $3(M=11.9)$ & Time $4(M=12.9)$ & Time $5(M=13.9)$ \\
\hline Body image dissatisfaction & $1.77(.89)$ & $1.86(.90)$ & $2.04(.92)$ & $2.10(.92)$ & $2.12(.89)$ \\
\hline Self-esteem & $3.49(.70)$ & $3.43(.69)$ & $3.40(.67)$ & $3.44(.67)$ & $3.49(.67)$ \\
\hline \multicolumn{6}{|c|}{ Girls $(n=1,060)$} \\
\hline Body image dissatisfaction & $1.99(.93)$ & $2.13(.98)$ & $2.41(.99)$ & $2.50(.99)$ & $2.50(.97)$ \\
\hline Self-esteem & $3.48(.65)$ & $3.48(.68)$ & $3.41(.67)$ & $3.44(.67)$ & $3.44(.66)$ \\
\hline
\end{tabular}

defined adolescence as "the period of human development that starts with puberty (10-12 years of age) and ends with physiological maturity (approximately 19 years of age)"(APA, 2007). The present study operationally defined time $1\left(4^{\text {th }}\right.$ grade of elementary school; age 9.9) as preadolescence and

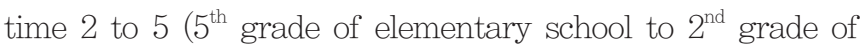
middle school; age 10.9 to 13.9) as early adolescence.

Several steps addressing attrition and missing data were taken to select the final sample for this study. First, for 2,826 children (1,511 boys and 1,315 girls) who participated at Time 1 (baseline), we removed data from 135 (4.8\%) who did not participate in the survey at Time 2. We also deleted 13 cases with missing values $(.4 \%)$ on either body image dissatisfaction or self-esteem. Of the 2,678 participants, 97 (3.6\%) did not participate in the survey at Time 3 and were removed from the sample. One case with missing data was also excluded. At Time 4, 2,580 adolescents, 191 (7.4\%) had not completed the interview and were deleted from the sample. However, no case had missing data on the variables of interest. At Time 5, 2,389 participants, 159 (6.7\%) ceased their participation, with no cases with missing data on the variables of interest. The final sample of 2,230 participants (1,170 boys and 1,060 girls) had complete data. To ensure the national representativeness of the final sample, $t$-tests examining differences between the participation group and the attrition group were conducted (Tabachnick \& Fidell, 2007). There were no significant differences on selfesteem and body image dissatisfaction at baseline between the participation group $(n=2,230)$ and the attrition group ( $n=596)$, which supports the generalizability of findings of the present study to the target population of Korean pre- and early adolescents. The average age of the participants was 9.9 years at Time 1, 10.9 at Time 2, 11.9 at Time 3, 12.9 at Time 4 , and 13.9 at Time 5.

\section{Measures}

Body image dissatisfaction. Three KYPS items measured body image dissatisfaction: "I am under stress because I am overweight or underweight," "I am under stress because I am too tall or too small," and "I am under stress because of my face." Respondents rated items on a 5-point Likert scale (1=never to 5=always), and each participant's mean score for the three body image dissatisfaction items was computed. Higher scores indicate a higher level of body image dissatisfaction. The scale showed adequate internal consistency, with a Cronbach alpha of .73 for boys and .71 for girls at Time 1, .77 for boys and .73 for girls at Time 2, .77 for boys and .73 for girls at Time 3, .77 for boys and .75 for girls at Time 4, and .75 for boys and .76 for girls at Time 5 .

Self-esteem. Six KYPS items measured self-esteem: "I think I am a good-natured person," "I think I am a person of ability," "I think I am a valuable person," "Sometimes I think I am a person of no use," "Sometimes I think I am a bad person," and "By and large, I feel like a failure." Respondents rated the items on a 5-point Likert scale ( $1=$ strongly disagree to $5=$ strongly agree). The three negatively worded items were reverse coded for scoring. Each respondent's mean score for the six items was calculated, with higher scores indicating higher self-esteem. The internal consistency of the scale was adequate, with Cronbach alphas of .75 for boys and .76 for girls at Time 1, .77 for boys and .78 for girls at Time 2, .74 for boys and .78 


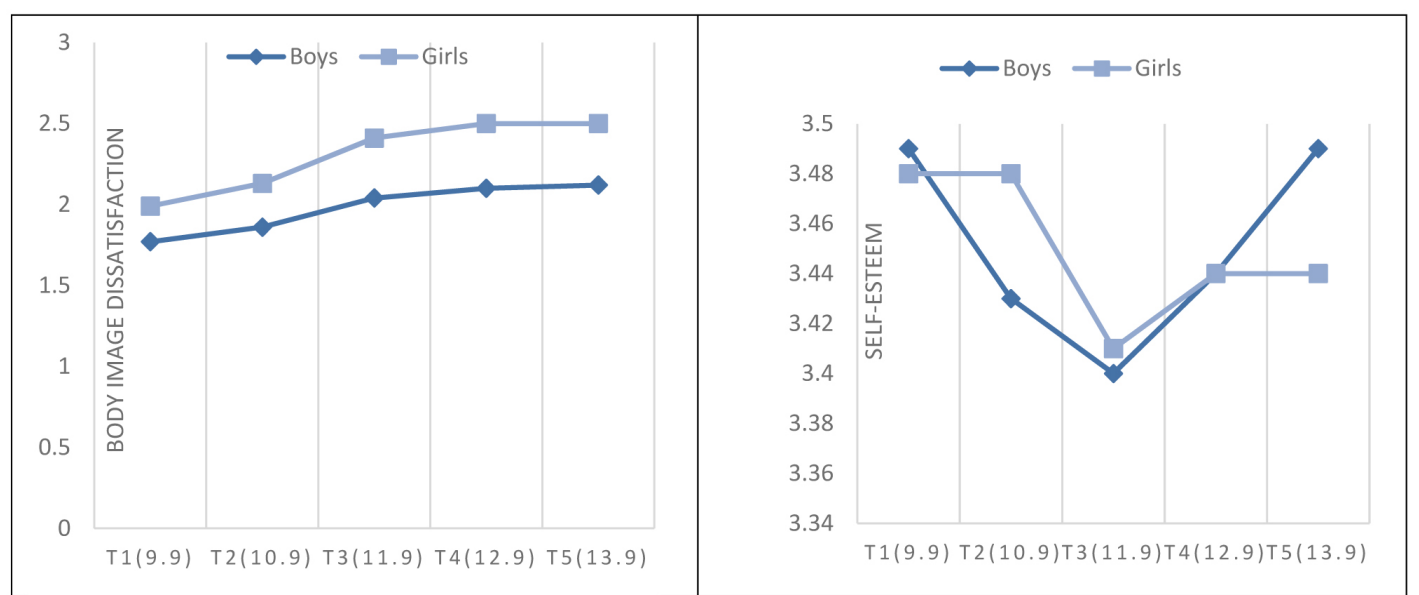

Figure 1. Change in mean scores of body image dissatisfaction and self-esteem over time.

Table 2. Correlations between Body Image Dissatisfaction and Self-esteem within Time and across Time

\begin{tabular}{|c|c|c|c|c|c|c|c|c|c|c|}
\hline & $\begin{array}{c}\text { Time1 } \\
(M=9.9) \\
\text { SE }\end{array}$ & $\begin{array}{c}\text { Time2 } \\
(10.9) \\
\text { SE }\end{array}$ & $\begin{array}{c}\text { Time3 } \\
(11.9) \\
\text { SE }\end{array}$ & $\begin{array}{c}\text { Time4 } \\
(12.9) \\
\text { SE }\end{array}$ & $\begin{array}{c}\text { Time5 } \\
(13.9) \\
\text { SE }\end{array}$ & $\begin{array}{c}\text { Time1 } \\
(M=9.9) \\
\text { BID }\end{array}$ & $\begin{array}{c}\text { Time2 } \\
(10.9) \\
\text { BID }\end{array}$ & $\begin{array}{c}\text { Time3 } \\
(11.9) \\
\text { BID }\end{array}$ & $\begin{array}{c}\text { Time4 } \\
(12.9) \\
\text { BID } \\
\end{array}$ & $\begin{array}{c}\text { Time5 } \\
\text { (13.9) } \\
\text { BID }\end{array}$ \\
\hline Time $1 \mathrm{SE}$ & 1 & .40 & .36 & .27 & .24 & -.27 & -.17 & -.14 & -.09 & -.10 \\
\hline Time 2 SE & .47 & 1 & .42 & .29 & .26 & -.15 & -.30 & -.21 & -.12 & -.13 \\
\hline Time 3 SE & .38 & .43 & 1 & .41 & .36 & -.16 & -.21 & -.32 & -.20 & -.17 \\
\hline Time 4 SE & .25 & .33 & .46 & 1 & .47 & -.14 & -.18 & -.22 & -.28 & -.21 \\
\hline Time 5 SE & .30 & .31 & .41 & .49 & 1 & -.09 & -.15 & -.19 & -.20 & -.32 \\
\hline Time 1 BID & -.35 & -.27 & -.22 & -.15 & -.19 & 1 & .29 & .23 & .2 & .19 \\
\hline Time 2 BID & -.22 & -.34 & -.25 & -.18 & -.18 & .45 & 1 & .35 & .21 & .23 \\
\hline Time 3 BID & -.17 & -.24 & -.32 & -.22 & -.21 & .41 & .51 & 1 & .35 & .28 \\
\hline Time 4 BID & -.19 & -.15 & -.17 & -.27 & -.20 & .29 & .34 & .37 & 1 & .39 \\
\hline Time 5 BID & -.14 & -.13 & -.20 & -.23 & -.33 & .28 & .29 & .38 & .43 & 1 \\
\hline
\end{tabular}

Note. SE=self-esteem, BID=body image dissatisfaction; Upper and down sides of the diagonal line denotes correlations among boys and girls, respectively; All correlations were significant at $p<.001$.

for girls at Time 3, .77 for boys and .78 for girls at Time 4, and .77 for boys and .79 for girls at Time 5 .

\section{Results}

Age and gender differences in body image dissatisfaction and self-esteem

Table 1 and Figure 1 present the descriptive statistics for the study's variables. Two 2 by 5 (sex by age) mixed ANOVAs were computed, in which sex was a between- subjects factor and age was a within-subjects factor across assessment time points, with body image dissatisfaction as the dependent variable in one analysis and self-esteem as the dependent variable in the other. The analysis for body image dissatisfaction resulted in two significant main effects for sex and age, as well as a sex by age interaction. In the main effect for age $\left(F_{(4,8968)}=138.69, p<.001\right)$, body image dissatisfaction increased over time. In the main effect for sex $\left(F_{(1,2242)}=150.44, p<.001\right)$, girls' body image dissatisfaction was higher than boys'. Sex by age interaction $\left(F_{(4,8968)}=7.09\right.$, $p<.001)$ indicated that the degree of change in body image dissatisfaction with age during pre- and early adolescence 


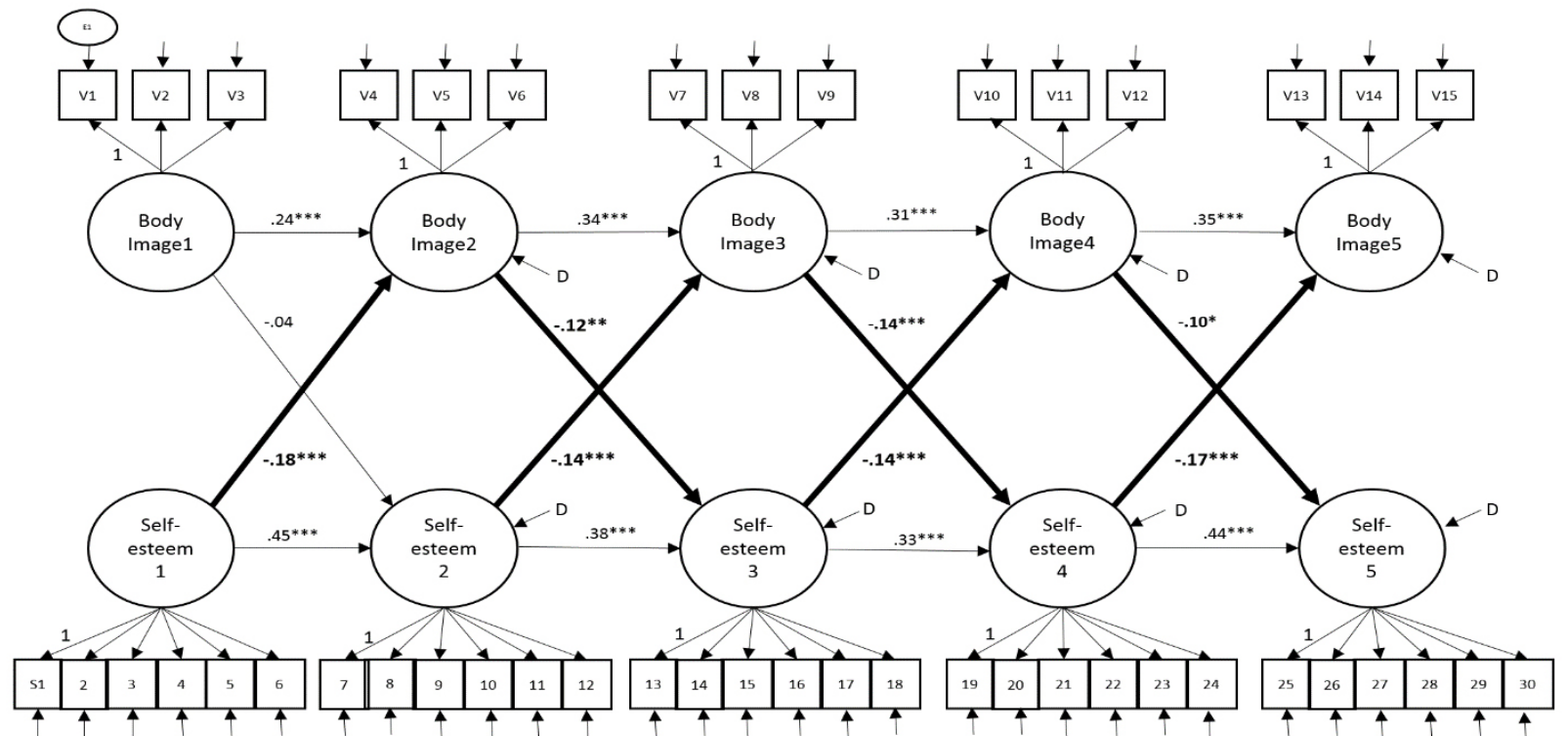

Figure 2. SEM for associations between body image dissatisfaction and self-esteem among boys. Note. Mean age of Time 1-5 are 9.9, 10.9, 11.9, 12.9, and 13.9, respectively.

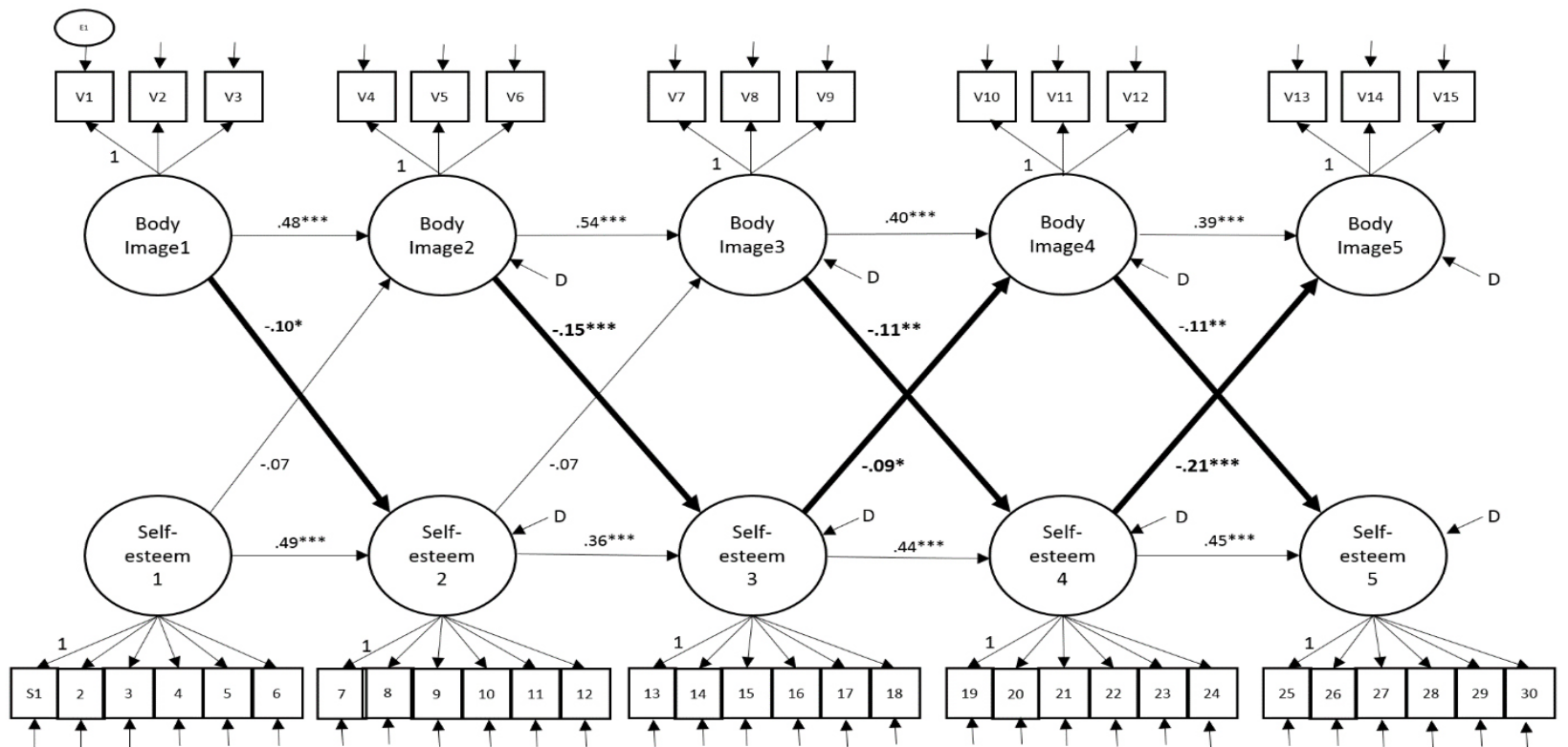

Figure 3. SEM for associations between body image dissatisfaction and self-esteem among girls. Note. Mean age of Time 1-5 are 9.9, 10.9, 11.9, 12.9, and 13.9, respectively.

depended on gender. Girls were shown to experience more rapid increases in their body image dissatisfaction than did boys.

In the 2 by 5 mixed ANOVA for self-esteem, the main effect of age was significant $\left(F_{(4,8968)}=6.66, p<.001\right)$. However, tests of within-subjects contrasts showed that the trend of the change was quadratic and not linear $\left(F_{(1,}\right.$ $\left.{ }_{2242)}=21.54, p<.001\right)$. The self-esteem of participants decreased during the first two years and increased later. However, whereas boys showed a clear U-shape pattern of change, girls' self-esteem did not return to the initial level. The main effect of sex on self-esteem was not significant $\left(F_{(1,}\right.$ $\left.{ }_{2242)}=.005, p=.944\right)$; neither was sex by age interaction $\left(F_{(1 .}\right.$ $\left.{ }_{8968)}=1.93, p=.102\right)$. 


\section{Cross-sectional and cross-lagged correlations}

Table 2 shows correlations between self-esteem and body image dissatisfaction within time and across time. All within-time and across-time correlations were significant $(p<.001)$. The significant but small to moderate correlations (.29-.39 for boys; .37-.51 for girls) of body image dissatisfaction across time shows the unstable development of body image dissatisfaction during pre- and early adolescence. For self-esteem, moderate correlations (.41-.47 for boys; .43-.49 for girls) also show a degree of instability for self-esteem. Correlations between body image dissatisfaction and self-esteem were also significant within time and across time regardless of gender; however, the degree of correlation was moderate overall (within-time correlations ranging from -.32 to -.27 for boys and -.35 to -.27 for girls).

\section{Examinations of longitudinal associations between body} image dissatisfaction and self-esteem

To investigate reciprocal influences between body image dissatisfaction and self-esteem, structural equation models testing body image dissatisfaction and self-esteem's effects on each other over time were employed. For boys, the model fit the data well, CFI=.95, NFI=.91, RMSEA=.03. Figure 2 shows the standardized coefficients. For girls, the model fit the data well, $\mathrm{CFI}=.95, \mathrm{NFI}=.91, \mathrm{RMSEA}=.03$. Figure 3 displays standardized coefficients among latent variables.

For boys, body image dissatisfaction significantly predicted self-esteem in later years, except for the time between time 1 and 2 (standardized coefficients: - 12 ( $p$ $<.01),-.14(p<.001),-.10(p<.05)$ during between time 2 and 5 , respectively). Self-esteem significantly predicted body image dissatisfaction in subsequent years during the entire period, with standardized coefficients being -.18 ( $p$ $<.001),-.14(p<.001),-.14(p<.001),-17(p<.001)$, respectively. The overall temporal relationship between body image and self-esteem was bidirectional and not unidirectional.

For girls, body image dissatisfaction longitudinally predicted self-esteem during the entire period (standardized coefficients $=-.10, p<.05 ;-.15, p<.001 ;-.11, p$ $<.01 ;-.11, p<.01)$. Self-esteem predicted body image dissatisfaction of the subsequent years only between time 3 and 5 , with standardized coefficients of $-.09(p<.05)$, $-.21(p<.001)$, respectively. The results show that at the beginning of the development, primarily body image dissatisfaction predicts self-esteem. However, a reciprocal relationship develops as they mature.

\section{Discussion}

The present study examined the longitudinal association between body image dissatisfaction and self-esteem among pre- and early adolescents. It also investigated how body image dissatisfaction and self-esteem change during preand early adolescence. The results are important because they provide a fine-grained picture of shifts that occur within pre- and early adolescence than has been apparent in previous studies. The study used nationally representative data that tracked the development of the same cohort of participants (born in 1994) for five years; therefore, the findings contribute to knowledge about longitudinal relationship regarding pre- and early adolescents' body image dissatisfaction and its relation to self-esteem.

In pre- and early adolescence, girls' body image dissatisfaction was significantly higher than boys'. This is consistent with previous studies on middle or late adolescence (Ata et al., 2007; Palmqvist \& Santavirta, 2006). Gender differences also increased as adolescents matured. This widened gap in body image dissatisfaction between girls and boys was also reported in preceding studies (Harter, 1999) and supports the view that body image is more negative among girls than boys during adolescence.

The trajectory of development of body image dissatisfaction was generally similar between boys and girls. Boys' body image dissatisfaction deteriorated during the first two years, but later stabilized. Harter's (1999) findings that only early adolescent boys, among the larger samples of boys 
aged 8 to 16, experienced worsened body image, is consistent with the present study. Similar to boys, girls' body image dissatisfaction increased as they grew older, particularly, during the first two years. The finding that female adolescents experienced a deteriorated body image during pre- and early adolescence was also found in previous studies (Clark \& Tiggemann, 2008; Harter, 1999); however, Clay et al. (2005) reported that the worsening of body image among girls became more obvious during middle adolescence rather than early adolescence. However, the findings of the current study's longitudinal design may be more reliable because those previous studies used cross-sectional comparisons rather than tracing the same cohort over time as in the present study. Thus, it is in pre- and early adolescence $\left(4-6^{\text {th }}\right.$ grade of elementary school) when adolescents experience the greatest negative changes in body image.

With regard to self-esteem, boys' and girls' self-esteem decreased during the first two years, reaching the lowest point at time 3 ( $6^{\text {th }}$ grade of elementary school), and then subsequently increased. The reason they continuously experience decreases in self-esteem and reach the lowest at time 3 may be that most secondary sexual features (e.g., pubic hair development) arise by this time (Coleman \& Coleman, 2002), which may abruptly disturb existing selfconcepts. Boys experienced sharper decreases than girls during this time. This may be because boys at age 9 to 11 are more likely to be exposed to negative interpersonal experiences such as parental corporal punishment (Gershoff, 2002; Straus \& Stewart, 1999) and bullying at school than girls (Seals \& Young, 2003); however, unlike girls, boys tend to hide painful feelings until they reach age 12 and fail to draw emotional support from friends and parents (Valkenburg, Sumter, \& Peter, 2011), which may decrease self-esteem.

The present study provides important descriptive information on the development of body image dissatisfaction and self-esteem during pre- and early adolescence; however, the study primarily focused on the longitudinal relationship between body image dissatisfaction and self-esteem. The results showed that reciprocal influences between body image dissatisfaction and self- esteem were prominent for both genders, while for girls the direction from body image dissatisfaction toward selfesteem was more salient, with the opposite direction emerging as they matured. This finding highlights that body image dissatisfaction and self-esteem develop in a circular manner, forming a vicious cycle between them over time, and do not develop independently of each other.

Body image dissatisfaction for girls predicted global self-esteem a year later during the entire period. This indicates that body/appearance becomes an important domain of life for girls as early as in preadolescence $\left(4^{\text {th }}\right.$ grade of elementary school), which coincides with the onset of puberty (mean age 9 to 11 for girls across studies) that is most frequently measured by breast bud and pubic hair development (Coleman \& Coleman, 2002). As girls experience such unprecedented physical changes, their body/appearance seems to become an important concern (Gatti et al., 2014) and integrated into their self-concept.

For boys, the effect of body image dissatisfaction on self-esteem becomes significant only after childhood, which seems plausible given that boys' secondary sexual characteristics represented by the onset of pubic hair and genital growth do not develop until they reach early adolescence (mean age 10 to 12 for boys across studies) (Coleman \& Coleman, 2002). However, their body seems to occupy the central part of their self-concept right after childhood, which is in line with Pope and colleagues' (2000) assertion that contemporary body image dissatisfaction has become common among adolescent boys as did girls, while it does not surface in society, since boys hide their body image concerns because of the norm that males should not disclose vulnerabilities.

Regarding the opposite direction, for boys, selfesteem predicted body image dissatisfaction a year later, which is consistent with Park \& Epstein' study (2013), but inconsistent with Paxton et al.'s (2006). The finding suggests that boys' global self-worth begins to permeate the evaluation of their body as early as in late childhood. This may be because, unlike other domains of self, such as scholastic competence and athletic competence, physical 
appearance has an omnipresent nature in that it is always present with the self. Therefore, attitudes and feelings toward the self may easily pervade those toward the body. For girls, the effect of self-esteem on body image dissatisfaction emerged as girls reached time $3\left(6^{\text {th }}\right.$ grade of elementary school). Before then, most girls may experience a variety of secondary sexual characteristics (breast bud development and menarche) (Coleman \& Coleman, 2002), which may make them intensely obsessed with their body (Gatti et al., 2014). Thus, they are likely to refer primarily to their body per se rather than taking external factors such as global self-worth into account when constructing their body image. Girls also tend to construct their body image by separately evaluating distinct body features (thighs, abdomen, breast, and hips), whereas boys evaluate their body based on the overall impression of their body (Koff et al., 1990). Therefore, it may be that girls' construction of body image is more dependent on objective reality of the body rather than on global feelings towards the self.

Sociocultural mechanisms may operate in regards to the path from body image dissatisfaction to self-esteem. Both genders may experience negative interactions regarding body/appearance such as, criticism, comparisons, and discrimination, in relation to their family and peers (Ata, Ludden, \& Lally, 2007; Haworth-Hoeppner, 2000; National Youth Policy Institute, 2008; Park, 2009; Phares, Steinberg, \& Thompson, 2004), which may degrade their self-esteem. Also, both genders may be exposed to various media through which they internalize pervasive social norms on body/appearance that girls and boys fulfilling thin-ideal and masculine-ideal, respectively, are much more valued by the society than others who fail to do so (Park, 2009; Pope, Phillips, \& Olivardia, 2000; Thompson et al., 1999).

From a cultural perspective, the results may highlight the body/appearance-centrism of Korean society. A negative association of body image dissatisfaction and selfesteem in adolescence has been observed across cultures; however, the association was not significant among Western preadolescents (Mendelson et al., 1996). The present study showed that even preadolescent girls as young as $4^{\text {th }}$ grade (age 9.9) can place a high value on the domain of body/ appearance that influences their global self-esteem one year later. This can be expected because Koreans are the most preoccupied with their body/appearance even among collectivist Asian peoples who are very self-conscious (Gim \& Ryu, 2012).

These findings have important implications for developing interventions for Korean pre- and early adolescents. First, the best timing for intervention regarding the deterioration of body image may be during the $1^{\text {st }}-2^{\text {nd }}$ grade of middle school because it is during that period that body image dissatisfaction reaches a peak for both females and males. However, in order to prevent body image dissatisfaction, actions ideally should be taken earlier, specifically during $5-6^{\text {th }}$ grade of elementary school. With regard to selfesteem, the appropriate time for intervention is during $6^{\text {th }}$ grade of elementary school; while prevention should be implemented during the $4-5^{\text {th }}$ grade of elementary school before the sharp decrease in self-esteem begins to occur.

Gender and age should be considered along with tailored treatment or education programs when designing specific content for prevention/intervention in a target population. For example, when one designs a multi-component program (Kazdin, 2003) to enhance self-esteem, for boys, the entire period except for $4^{\text {th }}$ grade of elementary school is appropriate to address body image dissatisfaction as a component. For girls, when intervening with self-esteem, given that body image dissatisfaction predicts self-esteem all through the years, it is proper to include the body image component in self-esteem enhancement programs anytime between 4th grade of elementary school and 2nd grade of middle school.

Conversely, when professionals want to design body image enhancement programs, the strategy to improve global self-esteem may be effective for boys regardless of time. However, for girls, because the effect of self-esteem on body image dissatisfaction emerges during between 6th grade of elementary school and 2nd grade of middle school, the self-esteem component needs to be included particularly for that period. 
This study is several limitations. First, as is often the case with nationally representative data, the measures used in this study are not standardized measures. Thus, they might have limited validity in reflecting adolescents' body image despite a high face validity. Future studies need to use validated measures to replicate these findings.

The ability to generalize the findings of the study may also be limited because contemporary Korean society is preoccupied with body appearance. Therefore, similar studies should be conducted in other cultures for cross cultural comparisons because the longitudinal associations between body image dissatisfaction and self-esteem may be weaker in a less body-centered culture than those in South Korea.

\section{Conclusions}

Despite the limitations, the present study contributes to knowledge on body image dissatisfaction and self-esteem in early adolescence. Nationally representative longitudinal panel data provided methodologically reliable findings on the directionality between body image dissatisfaction and selfesteem. The findings corroborate previous knowledge that body image dissatisfaction and self-esteem exert reciprocal influences. The present study also suggests that both age and gender should be taken into consideration to understand the relationship between body image dissatisfaction and selfesteem as well as to design effective inter-/preventions. For prevention purposes, education programs need to be implemented at the elementary school level rather than at the middle school level. Mental health professionals and relevant experts may use the study findings to effectively intervene in pre- and early adolescents' body image dissatisfaction and self-esteem issues.

\section{Declaration of Conflicting Interests}

The author declares no conflict of interest with respect to the authorship or publication of this article.

\section{Acknowledgments}

This Research was supported by Duksung Women's University Research Grants 2019.

\section{References}

Ata, R. N., Ludden, A. B., \&t Lally, M. M. (2007). The effects of gender and family, friend, and media influences on eating behaviors and body image dissatisfaction during adolescence. Journal of Youth and Adolescence, 36(8), 1024-1037.

Birkeland, M. S., Melkevik, O., Holsen, I., \& Wold, B. (2012). Trajectories of global self-esteem development during adolescence. Journal of Adolescence, 35(1), 43-54. https://doi.org/10.1016/ j.adolescence.2011.06.006

Brunet, J., Sabiston, C. M., Dorsch, K. D., \& McCreary, D. R. (2010). Exploring a model linking social physique anxiety, drive for muscularity, drive for thinness and self-esteem among adolescent boys and girls. Body Image, 7(2), 137-142. https://doi.org/10.1016/ j.bodyim.2009.11.004

Clark, L., \& Tiggemann, M. (2008). Sociocultural and individual psychological predictors of body image in young girls: A prospective study. Developmental Psychology, 44(4), 1124-1134. https://doi. org/10.1037/0012-1649.44.4.1124

Clay, D., Vignoles, V. L., \& Dittmar, H. (2005). Body image and selfesteem among adolescent girls: Testing the influence of sociocultural factors. Journal of Research on Adolescence, 15(4), 451-477. https:/ doi.org/10.1111/j.1532-7795.2005.00107.x

Cohen, D., \&t Hoshino-Browne, E. (2005). Insider and outsider perspectives on the self and social world. In R. Sorrentino, D. Cohen, J. Olson, \&t M. Zanna (Eds.), Culture and social behavior (pp. 49-76). Mahwah, NJ: Lawrence Erlbaum.

Coleman, L., \& Coleman, J. (2002). The measurement of puberty: A review. Journal of Adolescence, 25(5), 535-550. https://doi. org/10.1006/jado.2002.0494

Delfabbro, P. H., Winefield, A. H., Anderson, S., Hammarstrom, A., \& Winefield, H. (2011). Body image and psychological well-being in adolescents: The relationship between gender and school type. The Journal of Genetic Psychology, 172(1), 67-83. https://doi.org/10.1080/ 00221325.2010 .517812

Dorak, F. (2011). Self-esteem and body image of Turkish adolescent girls. Social Behavior and Personality, 39(4), 553-562. https://doi. org/10.2224/sbp.2011.39.4.553

Elkind, D. (1967). Egocentrism in adolescence. Child Development, 38(4), 
1025-1034. https://doi.org/10.2307/1127100

Frost, J., \& McKelvie, S. (2004). Self-esteem and body satisfaction in male and female elementary school, high school, and university students. Sex Roles, 51(1-2), 45-54.

Gatti, E., Ionio, C., Traficante, D., \&t Confalonieri, E. (2014). "I like my body; therefore, I like myself": How body image influences selfesteem-a cross-sectional study on Italian adolescents. Europe's Journal of Psychology, 10(2), 301-317. https://doi.org/10.5964/ejop. v10i2.703

Gershoff, E. T. (2002). Corporal punishment by parents and associated child behaviors and experiences: a meta-analytic and theoretical review. Psychological Bulletin, 128(4), 539-579.

Gim, W., \& Ryu, Y. (2012). Body image of Korean college students: Based on a cross-national study focusing on Korean, Chinese, and Japanese college students. Korean Journal of Psychological and Social Issues, 18(2), 301-327.

Han, S., \&t Kim, K. (2006). Influencing factors on self-esteem in adolescents. Journal of Korean Academy of Nursing, 36(1), 37-44. https://doi.org/10.4040/jkan.2006.36.1.37

Harter, S. (1999). The construction of the self: A developmental perspective. New York, NY: Guilford.

Haworth-Hoeppner, S. (2000). The critical shapes of body image: The role of culture and family in the production of eating disorders. Journal of Marriage and Family, 62(1), 212-227. https://doi. org/10.1111/j.1741-3737.2000.00212.x

Heinberg, L. J., \& Thompson, J. K. (1995). Body image and televised images of thinness and attractiveness: A controlled laboratory investigation. Journal of Social and Clinical Psychology, 14(4), 325338. https://doi.org/10.1521/jscp.1995.14.4.325

International Society of Aesthetic Plastic Surgeons. (2010). International survey on aesthetic/cosmetic procedures performed in 2010. Retrieved December 1, 2019, from http://www.isaps.org/news/isapsglobal-statistics

Jackson, T., \& Chen, H. (2010). Factor structure of the sociocultural attitudes towards appearance questionnaire-3 (SATA0-3) among adolescent boys in China. Body Image, 7(4), 349-355. https://doi. org/10.1016/j.bodyim.2010.07.003

James, W. (1890). Principles of psychology. Chicago: Encyclopedia Britannica.

Johnson, F., \& Wardle, J. (2005). Dietary restraint, body dissatisfaction, and psychological distress: A prospective analysis. Journal of Abnormal Psychology, 114(1), 119-125. https://doi.org/10.1037/0021843X.114.1.119

Kazdin, A. E. (2003). Research design in clinical psychology (4th ed.). Boston, MA: Allyn \& Bacon.

Kim, S., Yun, I., \& Kim, J. (2016). Associations between body weight and bullying among South Korean adolescents. Journal of Early Adolescence, 36(4), 551-574. https://doi. org/10.1177/0272431615577204

Koff, E., Rierdan, J., \& Stubbs, M. L. (1990). Gender, body image, and selfconcept in early adolescence. The Journal of Early Adolescence, 10(1), 56-68. https://doi.org/10.1177/0272431690101004

Kostanski, M., \& Gullone, E. (1998). Adolescent body image dissatisfaction: Relationships with self-esteem, anxiety, and depression controlling for body mass. Journal of Child Psychology and Psychiatry, 39(2), 255-262. https://doi.org/10.1017/ S0021963097001807

Makinen, M., Puukko-Viertomies, L., Lindberg, N., Siimes, M. A., \& Aalberg, V. (2012). Body dissatisfaction and body mass in girls and boys transitioning from early to mid-adolescence: Additional role of self-esteem and eating habits. BMC Psychiatry, 12(1), 1-8.

Mellor, D., McCabe, M., Ricciardelli, L., Yeow, J., Daliza, N., \&t Mohd Hapidzal, N. F. (2009). Sociocultural influences on body dissatisfaction and body change behaviors among Malaysian adolescents. Body Image, 6(2), 121-128. https://doi.org/10.1016/j.bodyim.2008.11.003

Mendelson, B. K., White, D. R., \&t Mendelson, M. J. (1996). Self-esteem and body esteem: Effects of gender, age, and weight. Journal of Applied Developmental Psychology, 17(3), 321-346. https://doi. org/10.1016/S0193-3973(96)90030-1

Mirza, N. M., Mackey, E. R., Armstrong, B., Jaramillo, A., \&t Palmer, M. M. (2011). Correlates of self-worth and bodysize dissatisfaction among obese Latino youth. Body Image, 8(2), 173-178. https://doi. org/10.1016/j.bodyim.2010.12.002

National Youth Policy Institute. (2008). The 3rd research on the level of human rights of Korean adolescents compared to international standards. Seoul, Korea: National Youth Policy Institute.

National Youth Policy Institute. (2010). Korean youth panel study (KYPS): 1st-5th year of panel study of 4th grade elementary school youths [Data file, code book, and user's guide]. Retrieved November 1, 2019, from https://www.nypi.re.kr/archive/brdartc//boardarticleList. do?brd_id=BDIDX_j1 peYiuN6Lf43009fG7W2vetsrch_ctgry_

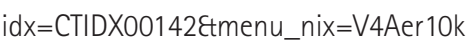

Nisbett, R. E. (2003). The geography of thought: How Asians and Westerners think differently...and why. New York, NY: Free Press.

Organization for Economic Co-operation and Development (OECD). (2011). Health at a Glance 2011: OECD Indicators [Data file]. Retrieved November 1, 2019, from http://www.oecd.org/els/healthsystems/49084488.pdf

Palmqvist, R., \& Santavirta, N. (2006). What friends are for: The relationships between body image, substance use, and peer influence among Finnish adolescents. Journal of Youth and Adolescence, 35(2), 203-217. 
Phares, V., Steinberg, A. R., \& Thompson, J. K. (2004). Gender differences in peer and parental influences: Body image disturbance, self-worth, and psychological functioning in preadolescent children. Journal of Youth and Adolescence, 33(5), 421-429.

Pope, H., Pope, H. G., Phillips, K. A., \&t Olivardia, R. (2000). The Adonis complex: The secret crisis of male body obsession. New York, NY: Free Press.

Park, W. (2009). The effects of adolescents' body mass index, selfesteem, family criticism and media exposure on their body image (Unpublished master's thesis). Yonsei University, Seoul, Korea.

Park, J. H., \& Choi, T. S. (2008). The effect of body image dissatisfaction on self-esteem in adolescents. Korean Journal of Play Therapy, 11, 117-129.

Park, W., \& Epstein, N. B. (2013). The longitudinal causal directionality between body image distress and self-esteem among Korean adolescents: The moderating effect of relationships with parents. Journal of Adolescence, 36(2), 403-411. https://doi.org/10.1016/ j.adolescence.2013.01.002

Paxton, S. J., Eisenberg, M. E., \&t Neumark-Sztainer, D. (2006). Prospective predictors of body dissatisfaction in adolescent girls and boys: A fiveyear longitudinal study. Developmental Psychology, 42(5), 888-899. https://doi.org/10.1037/0012-1649.42.5.888

Polce-Lynch, M., Myers, B. J., Kliewer, W., \& Kilmartin, C. (2001). Adolescent self-esteem and gender: Exploring relations to sexual harassment, body image, media influence, and emotional expression. Journal of Youth and Adolescence, 30(2), 225-244.

Polivy, J., \& Herman, C. P. (2002). Causes of eating disorders. Annual Review of Psychology, 53(1), 187-213. https://doi.org/10.1146/ annurev.psych.53.100901.135103

Seals, D., \& Young, J. (2003). Bullying and victimization: Prevalence and relationship to gender, grade level, ethnicity, self-esteem, and depression. Adolescence, 38(152), 735-747.

Shroff, H., \& Thompson, J. K. (2006). Peer influences, body-image dissatisfaction, eating dysfunction and self-esteem in adolescent girls. Journal of Health Psychology, 11(4), 533-551. https://doi. org/10.1177/1359105306065015

Shaw, H. E., Stice, E., \& Springer, D. W. (2004). Perfectionism, body dissatisfaction, and self-esteem in predicting bulimic symptomatology: Lack of replication. International Journal of Eating Disorders, 36(1), 41-47. https://doi.org/10.1002/eat.20016
Silverstone, P. H. (1992). Is chronic low self-esteem the cause of eating disorders? Medical Hypotheses, 39(4), 311-315. https://doi. org/10.1016/0306-9877(92)90054-G

Somerville, L. H., Jones, R. M., Ruberry, E. J., Dyke, J. P., Glover, G., \& Casey, B. J. (2013). The medial prefrontal cortex and the emergence of self-conscious emotion in adolescence. Psychological Science, 24(8), 1554-1562. https://doi.org/10.1177/0956797613475633

Statistics Korea. (2011). 2011 Adolescent statistics. Retrieved November 1, 2019, from http://kostat.go.kr/portal/korea

Straus, M. A., \&t Stewart, J. H. (1999). Corporal punishment by American parents: National data on prevalence, chronicity, severity, and duration, in relation to child and family characteristics. Clinical Child and Family Psychology Review, 2(2), 55-70

Sung, Y. S., Park, E. A., Lee, J. W., \&t Kim, W. S. (2009). Psychological power of beauty: Focused on gender difference and life-domain difference. Korean Journal of Consumer and Advertising Psychology, 10(3), 461-488.

Tabachnick, B. G., \&t Fidell, L. S. (2007). Using multivariate statistics (5th ed.). Boston, MA: Pearson Education.

Thompson, J. K., Heinberg, L. J., Altabe, M., \&t Tantleff-Dunn, S. (1999). Exacting beauty: Theory, assessment, and treatment of body image disturbance. Washington, D.C.: American Psychological Association.

Tiggemann, M. (2005). Body dissatisfaction and adolescent selfesteem: Prospective findings. Body Image, 2(2), 129-135. https://doi. org/10.1016/j.bodyim.2005.03.006

Valkenburg, P. M., Sumter, S. R., \&t Peter, J. (2011). Gender differences in online and offline self-disclosure in pre-adolescence and adolescence. British Journal of Developmental Psychology, 29(2), 253-269. https:// doi.org/10.1348/2044-835X.002001

American Psychological Association (APA). (2007). APA dictionary of psychology. Washington, DC: American Psychological Association.

Wardle, J., Haase, A. M., \&t Steptoe, A. (2006). Body image and weight control in young adults: International comparisons in university students from 22 countries. International Journal of Obesity, 30(4), 644-651.

Xu, X., Mellor, D., Kiehne, M., Ricciardelli, L. A., McCabe, M. P., \& Xu, Y. (2010). Body dissatisfaction, engagement in body change behaviors and sociocultural influences on body image among Chinese adolescents. Body Image, 7(2), 156-164. https://doi.org/10.1016/ j.bodyim.2009.11.003 